\title{
Stiffness Coefficients for Caisson Foundations Supporting Offshore Wind Energy Converters
}

\author{
AISSA Mohammed Hemza ${ }^{1}$, AMAR BOUZID .Djillali ${ }^{2}$
}

\begin{abstract}
A wide range of novel Offshore applications are emerging in the energy sector. Actually, Offshore Wind Energy is one of the most attractive sources of renewable energy. During the last decade, Offshore Wind Turbines were extensive application throughout the worldwide. However, the efficiency of Offshore Wind Turbines especially foundations in one of the currently challenges. In the past, suction caissons have been widely used in oil and gas structures. Recently it is attempted to be used as support structures for Offshore Wind Turbines.

Similarly to conventional monopiles, suction caissons supporting Wind Turbines experience lateral displacement mainly due to wind and waves, though studies show that caissons have more long term performance against loading.

This paper aims for highlighting the stiffness behavior of caissons in the elastic domain supporting Wind Turbines using the Fourier Series Aided Finite Element Method (FSAFEM) through sensitivity analysis considering the geometry of the caisson and variation of the soil stiffness with depth.
\end{abstract}

Keywords-Caissons, Wind Turbines, Stiffness, Finite Element Analysis.

\section{Introduction}

Monopiles and gravity base foundations are the most commonly used as support structures for Offshore wind turbines, althought caisson foundations are used increasingly for offshore structures (Cassidy et al., 2006) due to their economic advantages and usability in the recent few years.

The main objectif of this paper is to predict the response of laterally loaded cylindrical caisson by mean of stiffness coefficients in the elastic domain using Fourier Series Aided Finite Element Method (FSAFEM) which combines the conventional finite element method in the radial discretisation with the expansion of displacements and strains in Fourier series in the circumferential direction (Amar Bouzid et al., 2004; Abed et al., 2016; Aissa et al., 2017). The present study takes into account the slenderness ratio of the caisson and variation of soil stiffness with depth. Finally, we provide a simple illustration showing the usefulness of these stiffness coefficients.

\section{${ }^{1}$ PhD Student}

Department of Material Engineering, Faculty of Sciences and Technology, University of Medea

Algeria

${ }^{2}$ Professor

Department of Civil Engineering, Faculty of Technology, University Saad Dahleb of Blida

Algeria

\section{Fourier Series Aided Finite Element Method (FSAFEM)}

This so called semi analytical approach was proposed in a first time (Wilson, 1965) for FE analysis of axisymmetric structures loaded non-axisymmetrically. The main idea of this method is to use Fourier Series to resolve three dimensional problems as a two dimensional harmonic model and superposing each term result. We can found many applications of Semi-Analytical Approach in practical cases (See for example Kim et al., 1994; Zienkiewicz and Taylor, 2000). This method finds its applications in the present problem.

The nodal loads applied to a cylidrical caisson can be expanded in Fourier series as:

$\boldsymbol{R}=\overline{\boldsymbol{R}}_{\mathbf{0}}+\sum_{n=0}^{\infty} \bar{R}_{\boldsymbol{n}} \cos \boldsymbol{n} \theta+\overline{\bar{R}}_{\boldsymbol{n}} \sin \boldsymbol{\theta} \theta$

$Z=\bar{Z}_{0}+\sum_{n=0}^{\infty} \bar{Z}_{n} \cos n \theta+\bar{Z}_{n} \sin n \theta$

$T=\bar{T}_{0}+\sum_{n=0}^{\infty} \bar{T}_{n} \cos n \theta+\overline{\boldsymbol{T}}_{n} \sin n \theta$

Where $R, Z$ and $T$ are the radial, axial and circumferential components respectively with respect to the $\theta=0$ as plane of symmetry.

The displacement can be expressed in the form of Fourier series:

$u=\sum_{n=0}^{L} \bar{u}_{\mathrm{n}} \cos n \theta+\sum_{n=1}^{L} \overline{\bar{u}}_{n} \sin n \theta$

$v=\sum_{n=0}^{L} \bar{v}_{\mathrm{n}}+\sum_{n=1}^{L} \overline{\bar{v}}_{n} \sin n \theta$

$w=\sum_{n=0}^{L} \bar{w}_{\mathrm{n}} \cos n \theta+\sum_{n=1}^{L} \overline{\bar{w}}_{n} \sin n \theta$

Where $\bar{u}_{n}, \bar{v}_{n}, \bar{w}_{n}$ are the amplitudes of displacements that are symmetric with respect to the $(\theta=0)$ plane and $\overline{\bar{u}}_{n}, \overline{\bar{v}}_{n}, \overline{\bar{w}}_{n}$ are the amplitudes of displacement that are antisymmetric with respect to the $(\theta=0)$ plane, $n$ is harmonic number, and $L$ is the total number of harmonic terms considered in the series.

For a cylindrical caisson subjected to a lateral and/or an overturning moment, only the second term for $i=1$ survives, because this loading has a plane of symmetry. In this situation the components of loading in Eq. (1) reduce to:

$R=\bar{R} \cos \theta, Z=\bar{Z} \cos \theta, T=\bar{T} \sin \theta$

Where $\bar{R}, \bar{Z}$ and $\bar{T}$ are the amplitudes of nodal loading on the first harmonic. The load system displacements of Eq. (2) will reduce to:

$u=\bar{u} \cos \theta, \quad v=\bar{v} \cos \theta, \quad w=\bar{w} \sin \theta$

\section{Validation of the Computer Code CAISSON_LID}

A computer program called CAISSON_LID has been written in Fortran language (Fortran 90) for analyzing a cylindrical caisson subjected to lateral load and moment applied at the lid of the caisson. 
The model adopted for this study consists in a caisson with a slenderness ratio $d / R=2$. The thicknesses of the lid and skirt are respectively $t_{\text {lid }}=0.1 \mathrm{~m}$ and $t_{\text {skirt }}=0.03 \mathrm{~m}$. The Young's modulus of the caisson material is $E_{c}=2.10^{5} \mathrm{MPa}$ with a Poisson's ratio $v_{c}=0.25$, these values are corresponding to a steel material.

The soil material is considered as non homogeneous with a stiffness which varies linearly with depth (Gibson's soil). The elastic behavior of the medium is characterized by Young's modulus $E_{s}=60 \mathrm{MPa}$ and Poisson's ratio $v_{s}=0.499$

The geometric model adopted for this analysis consists of 848 eight nodes quadrilateral elements, therefore 2663 nodes including 29 elements in the $r$ direction and 28 in the $z$ direction. Limits of the geometrical model are in the order of $20 R$ in the $r$ direction and $2 d$ in the $z$ direction (Figure 1).

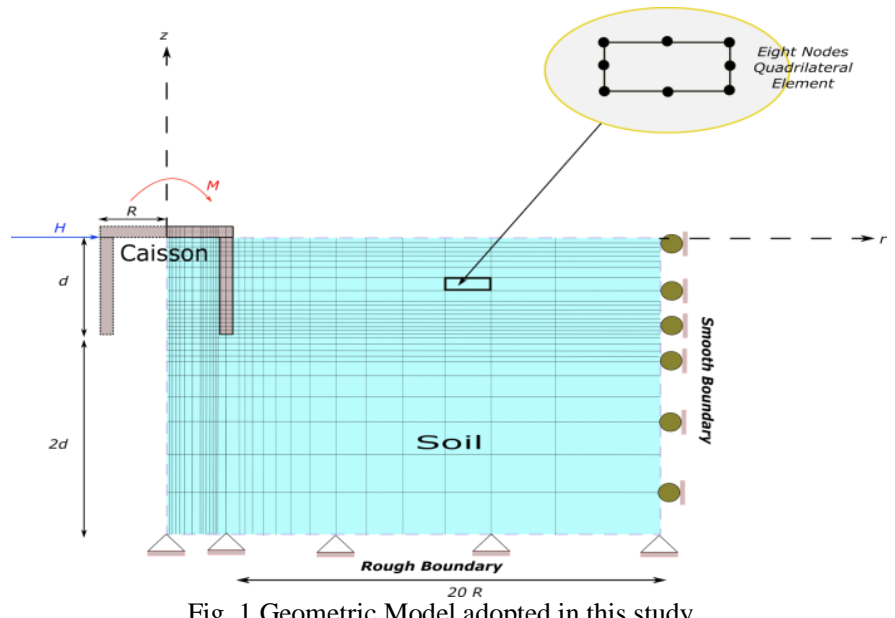

Fig. 1 Geometric Model adopted in this study.

Due to the large diameter of the caisson, we ensure a good accuracy by refining the mesh in caisson structure and in the interface area between the caisson and the soil

The computed stiffness coefficients $K_{H}, K_{M}$ and $K_{M H}$ are mentioned and compared with the results obtained by Doherty et al. (2005) in the Table I:

It is assumed that the flexible or the rigid behavior of a caisson is controlled by a parameter $S$, this dimensionless parameter is equal to:

$S=2\left(1+v_{s}\right) \cdot\left(E_{s} \cdot t_{\text {skirt }}\right) / E_{s} \cdot R$

To check this assumption, a parametric study is conducted firstly by variation of the Young's modulus of the soil $E_{s}$, Soil Poisson's ratio $v_{s}$ and the ratio $t_{\text {skirt }} / R$ are kept constant. However, the Young's modulus of the soil is varied to obtain different values of stiffness coefficients .

Thereafter, The stiffness coefficients $\left(K_{H}, K_{M}\right.$ and $\left.K_{M H}\right)$ are computed and plotted as function of $S$. The results of the present study are showed in the Figure 2 and compared with those obtained by Doherty et al. (2005):

\section{Iv. Analysis and discussion of the results}

Table I shows a negligible difference of stiffness coefficients between the computed results and results provided by Dohery et al. (2005), for a caisson with a radius $R=4 \mathrm{~m}$ and a skirt having a thickness $t_{\text {skirt }}=0.03 \mathrm{~m}$.

It is useful to introduce a parameter which depends on the characteristics of the soil and the caisson. This parameter is symbolized $\mathrm{S}$ representing the overall rigidity of the system, putting $S$ this parameter.

As shown in Figure 2, the stiffness coefficients $K_{H}, K_{M}$ and $K_{M H}$ vary exponentially as function of $S$. But, there is a domain for $S$ (Between 1 to $10^{-2}$ and between $10^{3}$ to $10^{5}$ ), which stiffness coefficients become constant and the curve constitute almost a horizontal line.

The increase of stiffness coefficient as function of $S$ explain how this parameter control the overall rigidity of the system soil-foundation, we can check from the graphs that the behavior of the caisson becomes rigid for a high values of $S$ and contarary for a small values of $S$ the behavior becomes flexible.

The comparison of the results obtained in the present study against those of Doherty et al. (2005) reflects that the Scaled Boundry Finite Element Method underestimates $K_{H}$ and $K_{M H}$ for a high values of $S$ it means in the rigid domain, furthermore, this method underestimate $K_{M}$ for a small values of $S$ it mean in the flexible domain.

\section{Illustrative Example}

In the present application, we take a caisson with a radius $R=12 \mathrm{~m}$ and a slenderness ratio $d / R=1$ as shown in the Figure 11.

The shear modulus of the soil $G_{s}=3.10^{3} \mathrm{kN}$ and his Poisson's ratio $v_{s}=0.2$. The thickness of the skirt $t_{\text {skirt }}=0.01 \mathrm{~m}$ and that of the lid $t_{\text {lid }}=0.1 \mathrm{~m}$

Assuming a horizontal load $H=4.10^{3} \mathrm{kN}$ acting at a height of $20 \mathrm{~m}$ from the seabed level, resulting in overturning moment $M=8.10^{4} \mathrm{kN}$.

The stiffness coefficients which correspond for this example are: $K_{H}=10.7035, K_{M}=18.4574$ and $K_{M H}=-8.9605$.

Furthermore it is easy to obtain the lateral displacement $u$ and his deflection $\theta$ :

$u=\left(K_{M} / K_{M} K_{H}-K_{M H}^{2}\right)\left(H / G_{s} R\right)-\left(K_{M H} / K_{M} K_{H}-K_{M H}^{2}\right)\left(M / G_{s} R^{2}\right)$

(6)

$\theta=\left(K_{H} / K_{M} K_{H}-K_{M H}^{2}\right)\left(M / G_{S} R^{3}\right)-\left(K_{M H} / K_{M} K_{H}-K_{M H}^{2}\right)\left(H / G_{S} R^{2}\right) \quad$ (7)

By substituting the stiffness coefficients $K_{H}, K_{M}$ and $K_{M H}$, the shear modulus $G_{s}$ and the poisson's ratio of the soil $v_{s}$, the caisson's radius $R$, the horizontal loading $H$ and the overturning moment $M$ in eq.(6) and eq.(7), we have:

$u=3,5 \cdot 10^{-2} \mathrm{~m}$

$\theta=23,3 \cdot 10^{-4} \mathrm{rad}$

Table II provides a comparison between the computed results and those obtained by Doherty and Deeks (2003): 
Proc. of Eighth International Conference On Advances in Civil, Structural and Mechanical Engineering - ACSM 2018 Copyright $(\odot$ Institute of Research Engineers and Doctors, USA. All rights reserved.

ISBN: 978-1-63248-154-2 doi: 10.15224/978-1-63248-154-2-11

TABLE I. Computed stiffness coefficients for an embedded caisson in Gibson's soil.

\begin{tabular}{|c|c|c|c|}
\hline Stiffness Coefficient & Present Study & Doherty et al. (2005) & Difference (\%) \\
\hline $\boldsymbol{K}_{\boldsymbol{H}}$ & 13.13 & 12.67 & 3.50 \\
\hline $\boldsymbol{K}_{\boldsymbol{M}}$ & 45.59 & 42.09 & 7.67 \\
\hline $\boldsymbol{K}_{\boldsymbol{M} \boldsymbol{H}}$ & -12.31 & -12.75 & 3.45 \\
\hline
\end{tabular}

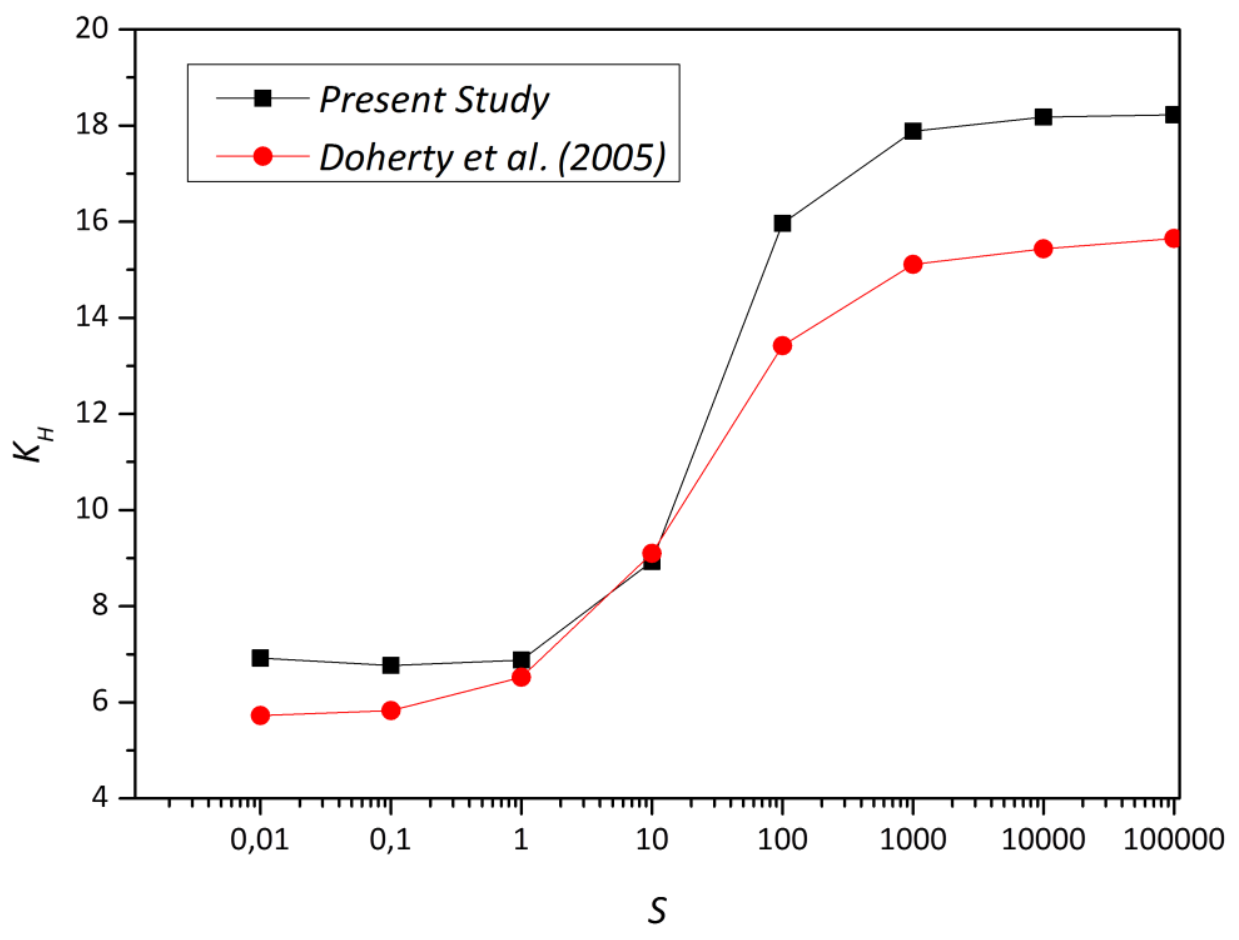

(a) 
Proc. of Eighth International Conference On Advances in Civil, Structural and Mechanical Engineering - ACSM 2018 Copyright $(\odot$ Institute of Research Engineers and Doctors, USA. All rights reserved.

ISBN: 978-1-63248-154-2 doi: 10.15224/978-1-63248-154-2-11

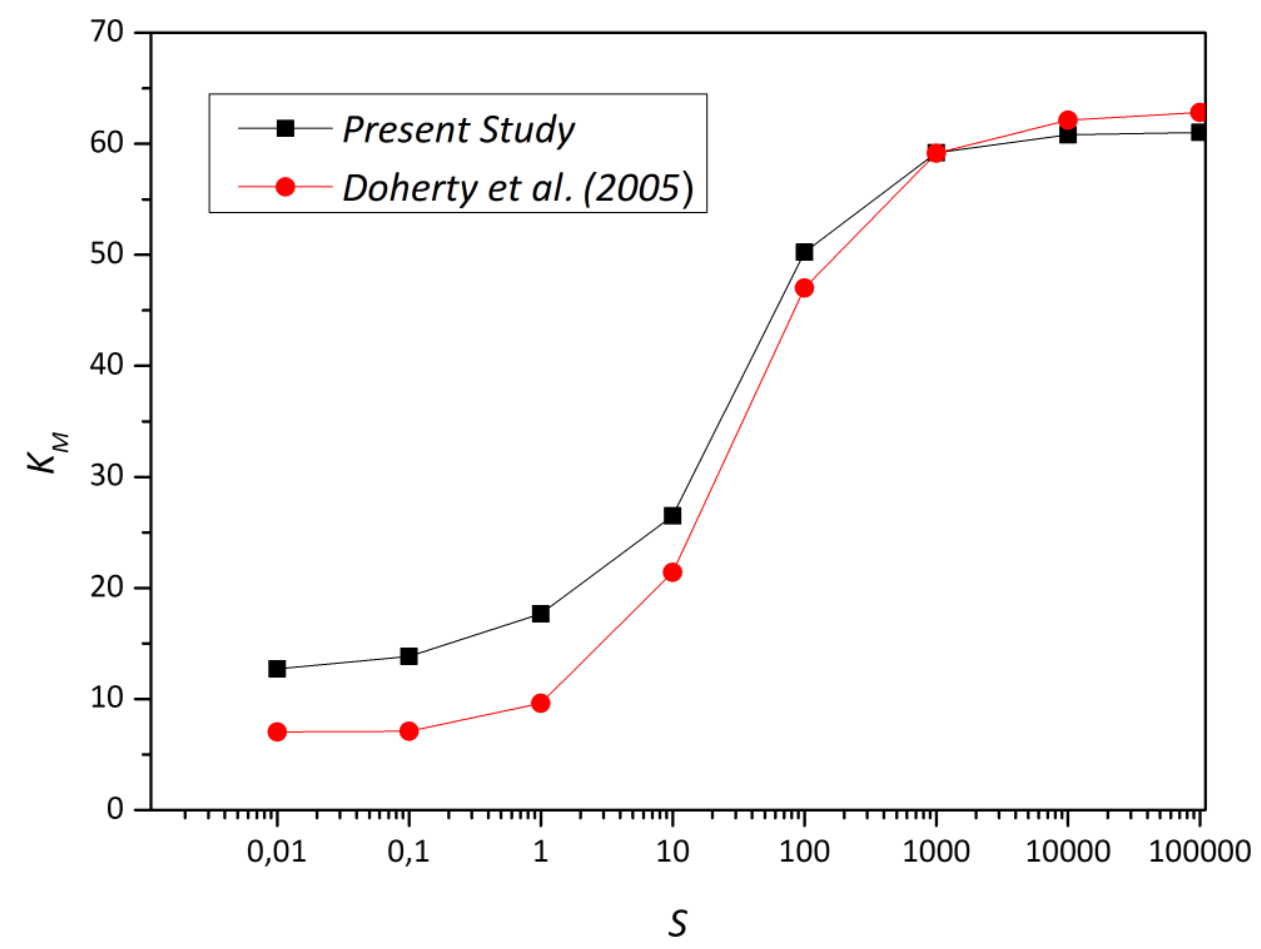

(b)

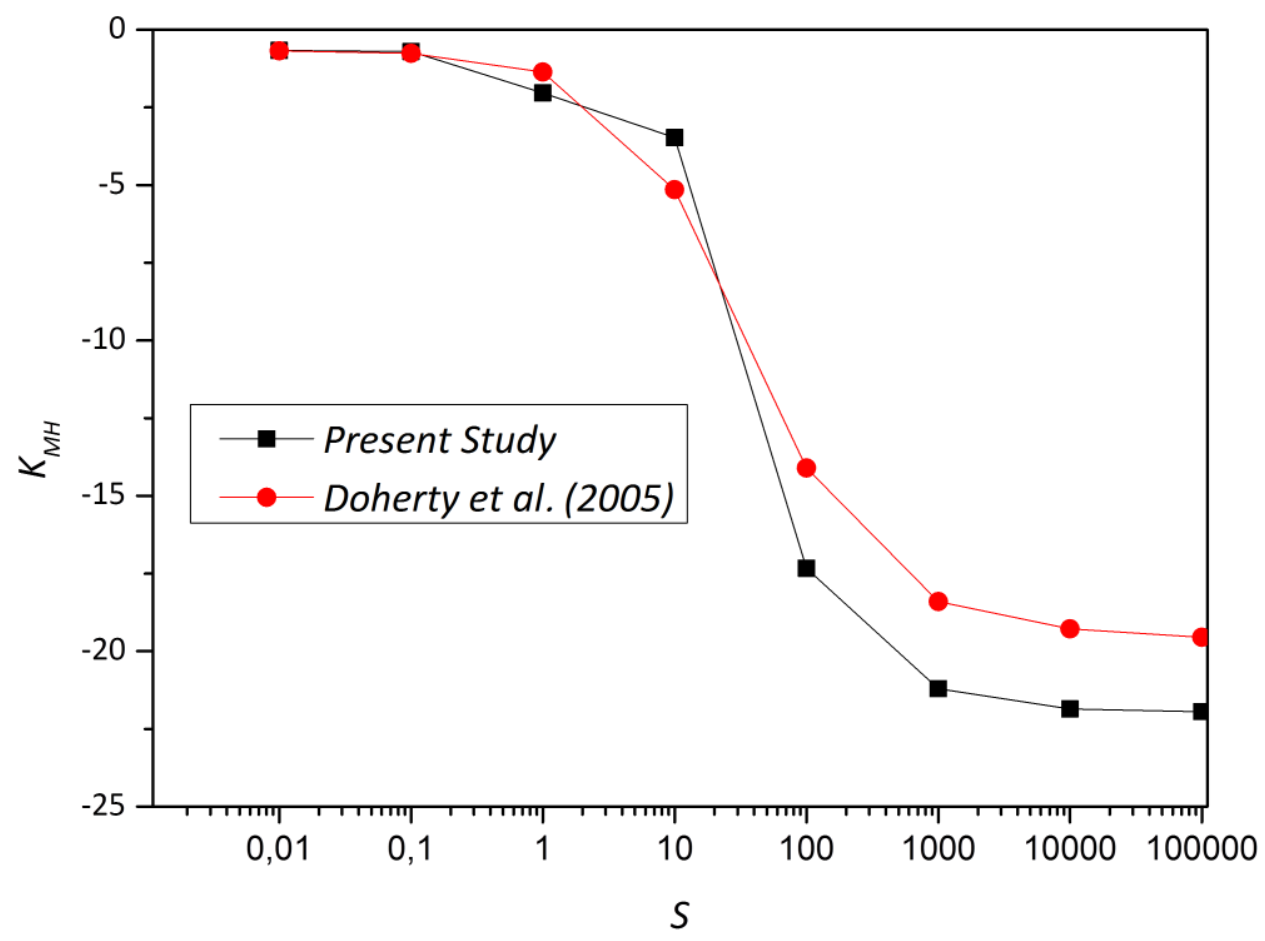

(c)

Fig. 2 Stiffness Coefficients, (a) $K_{H}$, (b) $K_{M}$ and (c) $K_{M H}$ for a skirted caisson embedded in a Gibson soil with $v_{s}=0.499$ 
Proc. of Eighth International Conference On Advances in Civil, Structural and Mechanical Engineering - ACSM 2018

Copyright $($ Institute of Research Engineers and Doctors, USA. All rights reserved.

ISBN: 978-1-63248-154-2 doi: 10.15224/978-1-63248-154-2-11

TABLE II. Displacement and Deflection Computed in the present example.

\begin{tabular}{|c|c|c|c|}
\hline & Present Study & Doherty and Deeks. (2005) & Difference (\%) \\
\hline $\boldsymbol{u}(\mathrm{m})$ & $3,5.10^{-2}$ & $3,3.10^{-2}$ & 5,71 \\
\hline $\boldsymbol{\theta}(\mathrm{rad})$ & $23,3.10^{-4}$ & $20,0.10^{-4}$ & 14,16 \\
\hline
\end{tabular}

As we can see in table II, a small difference is noticed between results of the present study and those obtained by Doherty and Deeks (2005).

\section{- Conclusion}

The linear behavior of a skirted caisson laterally loaded in the elastic domain has been exploited in this paper. Fourier Series Aided Finite Element Method is used in this work to address the problem. This approach combines the finite element method which is based on the use of $2 \mathrm{D}$ discretisation in the radial direction with the expansion of displacements and loads in Fourier series in the circumferential direction. This method is used to identify the overall behavior of the system caissonsurrounding soil by means of stiffness coefficients. Different soil profiles and caisson's geometries are considered to achieve this analysis. The present study gives excellent results compared with previous existing works. This confirms the efficiency of the method used in the analysis. Finally, a simple example is provided to show the utility of the proposed solutions.

\section{References}

[1] Abed, Y., Amar Bouzid, Dj., Bhattacharya, S. and Aissa, M.H. (2016). Static Impedance Functions for Monopiles Supporting Offshore Wind Turbines in Nonhomogeneous Soils-Emphasis on Soil/Monopile Interface Characteristics. Earthquakes and Structures, 10, 1143-1179.

[2] Aissa, M.H., Amar Bouzid, Dj. and Bhattacharya, S. (2017). Monopile Head Stiffness for Serviceability Limit State Calculations in Assessing the Natural Frequency of Offshore Wind Turbines. International Journal of Geotechnical Engineering, ISSN:1938-6362.

[3] Amar Bouzid, Dj., Tiliouine, B. and Vermeer, P.A. (2004). Exact Formulation of Interface Stiffness Matrix of Axisymmetric Bodies under non-Axisymmetric Loading. Computers and Geotechnics, 31, 75-87.

[4] Bintian, J., Xiaobing, L. and Zhongmin, S. (2010). On the Bearing Capacity of Suction Bucket Foundations in Saturated Sand. Journal of Ocean Engineering, 3, 45-49.

[5] Booker, J.R., Balaam, N.P. and Davis, E.H. (1985). The Behavior of an Elastic non Homogenous Half-Space. International Journal of Numerical Analysis Methods in Geomechanics, 353-367.
[6] Byrne, B.W. (2000). Investigation of Suction Caissons in Dense Sand. PhD Thesis, University of Oxford.

[7] Byrne, B.W. and Houlsby, G.T. (2003). Foundations for Offshore Wind Turbines. Philosophical Transactions of the Royal Society of London, Series A 361, December, 2909-2930.

[8] Cassidy, M.J., Randolph, M.F. and Byrne, B.W. (2006). A Plasticity Model Describing Caisson Behavior in Clay. Journal of Applied Ocean Research, 28, 345-358.

[9] Cook, R.D., Malkus, D.S., Plesha, M. E. and Witt, R. J. (2002). Concepts and applications of finite element analysis, New York, NY, Wiley.

[10] Doherty, J.P. and Deeks, A.J. (2003). Elastic Response of Circular Footings Embedded in a Non-Homogeneous Half-Space. Géotechnique, 53, 703-714.

[11] Doherty, J.P., Houlsby, G.T. and Deeks, A.J. (2005). Stiffness of Flexible Caisson Foundations Embedded in Non-Homogeneous Elastic Soil. Journal of Geotechnical \& GeoEnvironmental Engineering, 131, 1498-1508.

[12] Kim, D.S., Bouchalkha, A., Jacob, J.M., Zhou, J.F., Song, J.J. and Klem, J.F. (1994). Confined to propagating transition of LO phonons in $\mathrm{GaAs} / \mathrm{Al}_{\mathrm{x}} \mathrm{Ga}_{1-\mathrm{x}} \mathrm{As}$ superlattices observed by picosecond Raman scattering. Physical Review Letters, 10, 15-72.

[13] Maniar, D.R. (2004). A Computational Procedure for Simulation of Suction Caisson Behavior Under Axial and Inclined Loads. PhD Thesis, The University of Texas at Austin.

[14] Monajemi, H. and Abdul Razak, H. (2009). Finite Element Modeling of Suction Anchors Under Combined Loading. Marine Structures, 22, 660-669.

[15] Wilson, E.L. (1965). Structural Analysis of Axisymmetric Solids. Proceeding $2^{\text {nd }}$ Aerospace Sciences Meeting, New York, 65-143.

[16] Zienkiewicz, O.C. and Taylor, R.L. (2000). The Finite Element Method: The Basis. Vol.1, $5^{\text {th }}$ Edition, Butterworth-Heinemann.

[17] Zhan, Y.G and Liu, F.C. (2010). Numerical Analysis of Bearing Capacity of Suction Bucket Foundation for Offshore Wind Turbines. Electronic Journal of Geotechnical Engineering, 15, 633643. 